\title{
The impact of in situ breast cancer and family history on risk of subsequent breast cancer events and mortality - a population- based study from Sweden
}

Helena Sackey ${ }^{1,6^{*}}$, Miao Hui ${ }^{2}$, Kamila Czene ${ }^{3}$, Helena Verkooijen ${ }^{4}$, Gustaf Edgren ${ }^{3,7}$, Jan Frisell ${ }^{1,6}$ and Mikael Hartman 1,2,5

\begin{abstract}
Background: The clinical behavior of in situ breast cancer is incompletely understood and several factors have been associated with invasive recurrence. The purpose of this study was to evaluate long-term risk of subsequent breast cancer and mortality among women diagnosed with in situ breast cancer, in relation to family history

Methods: Using the population-based Swedish Multi-Generation and Cancer Registers we identified 8111 women diagnosed with in situ breast cancer between 1980 and 2004. We used standardized incidence ratios (SIRs) to measure the relative risk of subsequent invasive or contralateral in situ breast cancer and standardized mortality ratios (SMRs) for relative risks of death.

Results: Among women diagnosed with in situ breast cancer, the cumulative 10-year and 20-year risk for subsequent contralateral or ipsilateral invasive cancer was approximately $10 \%$ and $18 \%$, respectively. The risk of subsequent invasive breast cancer was increased more than 4-fold (SIR 4.6 (95\% Cl 4.2 - 4.9)) among women with in situ breast cancer as compared to women in the general population and the risk of contralateral in situ breast cancer was increased almost 16-fold (SIR 16.0 (95 \% Cl 13.2-19.1)). Having a family history of breast cancer increased the risk of contralateral invasive breast cancer by almost $50 \%$ (incidence rate ratio $1.5(95 \% \mathrm{Cl} 1.0-2.0)$ ). Women under forty years old at diagnosis, without family history, had a 7-fold increased risk, and those with a family history had a 14-fold increased risk for subsequent invasive breast cancer with SIRs of 7.2 (95 \% Cl 4.8-10.5) and 14.3 (95\% Cl 7.4-25.0), respectively. The overall risk of death in women with in situ breast cancer was significantly increased by $30 \%$ compared to the general population but was highly dependent on the occurrence of a second invasive cancer event (SMR 1.3 (95 \% Cl 1.2-1.4)).

Conclusions: Among women with in situ breast cancer, a positive family history increases the risk of contralateral invasive breast cancer by almost $50 \%$. The risk of subsequent invasive breast cancer and mortality is substantially higher in younger women, which should be taken into account when planning their treatment and follow up.
\end{abstract}

Keywords: In situ breast cancer, Mortality, Second event, Contralateral breast cancer

\footnotetext{
* Correspondence: helena.ikonomidis-sackey@karolinska.se

'Department of Molecular Medicine and Surgery, Karolinska Institutet, Stockholm, Sweden

${ }^{6}$ Department of Breast and Endocrine Surgery, Karolinska University Hospital, Stockholm, Sweden

Full list of author information is available at the end of the article
} 


\section{Background}

Women with in situ breast cancer have an increased risk of developing in situ or invasive breast cancer in the ipsilateral or contralateral breast [1-12]. Moreover women with in situ breast cancer, even after treatment, are at increased risk of subsequent invasive breast cancer compared to women in the general population $[1,3-9,13-16]$. The clinical behavior of in situ breast cancer is incompletely understood but it is likely that it represents a mixed population of indolent and more aggressive tumors. Several factors have been associated with invasive recurrences, including patient characteristics $[4,5,8]$, tumor characteristics $[4,5,17]$ and treatment $[4,18,19]$. The influence of a positive family history on subsequent breast cancer is less well-studied [20-22].

The risk of death from breast cancer in women diagnosed with in situ breast cancer is considered to be at most only marginally increased, but remains less wellcharacterized and, with few exceptions, studies are often limited by short follow up and non-population-based designs $[14,23]$. In this study we evaluated the long-term risk of second breast cancer and death among women diagnosed with in situ breast cancer, in relation to family history.

\section{Methods}

We combined data from the Multi-Generation Register (including more than 11 million individuals, from around 3 million families) with the Swedish Cancer Register, the Cause of Death Register and the Total Population Register for data on emigration. These registers were merged using the unique national registration number that all Swedish citizens receive at birth or immigration. Linkages provide complete follow up with of cancers, vital status, date and cause of death, and dates of immigration and emigration. It also provides links between children and parents through their respective national registration numbers.

The Swedish Cancer Register is a nationwide, population-based register that contains information on virtually all diagnosed cancers in Sweden since 1958 and is considered almost complete for invasive cancer [2426] and of very high reliability for in situ breast cancer from 1980 onwards [26]. The tumor site is classified according to international classification of disease (ICD). Any invasive cancer following in situ breast cancer is reported as a new event, as are new in situ breast cancers in the contralateral breast. Local relapses are not recorded, neither are new ipsilateral in situ events. The register does not distinguish ductal from lobular in situ breast cancer before 1990 and contains no information on tumor stage or treatment. Ipsilateral in situ breast cancer was excluded due to the increased probability of being underreported in women with previous in situ breast cancer.
Thus, we defined subsequent breast events as ipsilateral or contralateral invasive or a contralateral in situ breast cancer. Women with any previous invasive or in situ breast cancer were excluded, as were women with invasive breast cancer diagnosed concurrently with the first in situ breast cancer. Family history of breast cancer was defined as having at least one first-degree relative diagnosed with invasive breast cancer at any point in time. For all women, we collected information on family history of breast cancer and all second primary cancers including type of cancer, laterality and date of diagnosis. Because of incomplete information on laterality and in situ breast cancer registration prior to 1980 [26], we restricted our cohort to women with a first in situ breast cancer diagnosed in the period 1980 to 2004. Our final study population consisted of 8111 women in the Swedish Multi-Generation Register, diagnosed with first in situ breast cancer between 1 January 1980 and 1 January 2005.

\section{Statistical analyses \\ Risk of subsequent breast events following in situ breast cancer}

To estimate the risk of a subsequent breast event (ipsilateral or contralateral invasive or contralateral in situ breast cancer), all women were followed from the date of their first in situ breast cancer diagnosis and continued until a subsequent breast cancer, emigration, death, or end of follow up, whichever came first. We estimated standardized incidence ratios (SIRs), i.e., the ratio of the observed to the expected number of breast cancers (ipsilateral or contralateral invasive or contralateral in situ breast cancer), as a measure of relative risk. The expected number of subsequent breast cancer events was calculated as the product of the person-years accumulated by women with in situ breast cancer by the age-specific and calendar-period-specific incidence of unilateral in situ/invasive breast cancer in the general population in the Swedish Multi-Generation Register.

For all estimates for the contralateral breast, the background rate of in situ and invasive breast cancer was divided by two, as only one breast was "at risk". Thus, SIRs compare sex-adjusted, age-adjusted and calendar-periodadjusted risk of subsequent events (ipsilateral or contralateral invasive or contralateral in situ breast cancer) among patients with in situ breast cancer to the risk among the general population, and were stratified by family history of breast cancer. SIRs of subsequent invasive breast cancer were calculated for the calendar period of the first diagnosis, age and time since first diagnosis. Poisson trend tests for monotonic trend of SIRs across calendar period, age and time since first diagnosis was performed [27]. We used Poisson regression modeling among women with a first in situ breast cancer to estimate the independent effects of age, year and time since diagnosis and effect of 
family history on the risk of ipsilateral or contralateral invasive or contralateral in situ breast cancer.

As background rates of breast cancer vary considerably by age we also estimated excess additive risks (EARs), as the difference of observed numbers of subsequent invasive breast cancers and the expected numbers in the general population in the Swedish Multi-Generation register, as a measure of absolute risk for subsequent invasive cancer. EARs were estimated using a univariate Poisson model with an identity link function and the expected number of cases as the offset. The likelihood ratio test was used to calculate $95 \%$ confidence intervals (CIs). The cumulative incidence was estimated using the life-table (actuarial) method.

\section{Risk of death following in situ breast cancer}

The standardized mortality ratio (SMR), i.e., the ratio of the observed to the expected number of deaths, standardized by age and calendar period, was used as a measure of relative mortality. The expected number of deaths was calculated from the general population in the Swedish Multi-Generation register. SMRs were also stratified by family history, age at first in situ breast cancer diagnosis and type of subsequent breast event. For overall SMRs, subjects were followed from the date of the first in situ breast cancer diagnosis until the date of emigration, death, or end of follow up, whichever came first. In contrast, in the estimates of death by type of subsequent breast event, follow up was started at the diagnosis of that particular event. We calculated $95 \%$ CIs assuming a Poisson distribution for the observed number of cases. All data preparation and analysis was done using the SAS statistical package, version 8.2 or higher (SAS Institute Inc., Cary, NC, USA). The regional ethical committee in Stockholm approved the study.

\section{Results}

Patient characteristics are listed in Table 1 . Over a followup period of 71,458 person-years, 825 (10.2 \%) women developed 886 subsequent breast events (118 contralateral in situ and 768 ipsilateral or contralateral invasive breast cancers). The proportion of subsequent breast events was similar in women with and without a family history $(11.3 \%, \mathrm{n}=97$ versus $10.0 \%, \mathrm{n}=728)$. The average time from the first in situ breast cancer diagnosis to a second breast event was overall 5.6 years $+/-4.6$ years.

\section{Risk}

Table 2 presents the risk of second invasive or in situ breast cancer. The risk of a subsequent ipsilateral or contralateral invasive breast cancer was increased more than fourfold (SIR 4.6 (95\% CI 4.2-4.9)) among women with in situ breast cancer as compared to women in the general population. The risk of contralateral in situ breast cancer was almost 16-fold increased (SIR 16.0 (95\% CI,
Table 1 Summary of all women diagnosed with in situ breast cancer from 1980 to 2004

\begin{tabular}{|c|c|c|c|}
\hline & All & $\begin{array}{l}\text { No family } \\
\text { history }\end{array}$ & $\begin{array}{l}\text { Family } \\
\text { history }\end{array}$ \\
\hline Total & 8111 & 7252 & 859 \\
\hline $\begin{array}{l}\text { Mean age at first in situ breast } \\
\text { cancer (SD) }\end{array}$ & $59.1(12.1)$ & $59.7(12.1)$ & $53.9(10.8)$ \\
\hline Mean follow-up time, years (SD) & $8.8(5.9)$ & $8.3(5.9)$ & $7.7(5.4)$ \\
\hline \multicolumn{4}{|c|}{ Year at diagnosis of first in situ cancer } \\
\hline $1980-1984$ & 665 & 624 & 41 \\
\hline $1985-1989$ & 1211 & 1108 & 103 \\
\hline $1990-1994$ & 2046 & 1835 & 211 \\
\hline $1995-1999$ & 1963 & 1727 & 236 \\
\hline $2000-2004$ & 2226 & 1958 & 268 \\
\hline \multicolumn{4}{|c|}{ Age at diagnosis of first in situ cancer, years } \\
\hline$<40$ & 335 & 269 & 66 \\
\hline $40-44$ & 594 & 507 & 87 \\
\hline $45-49$ & 1078 & 903 & 175 \\
\hline $50-54$ & 1313 & 1133 & 180 \\
\hline $55-59$ & 1133 & 993 & 140 \\
\hline $60-64$ & 1021 & 943 & 78 \\
\hline $65-69$ & 1058 & 995 & 63 \\
\hline $70-74$ & 778 & 748 & 30 \\
\hline $75+$ & 801 & 761 & 40 \\
\hline \multicolumn{4}{|l|}{ Type of second events } \\
\hline Contralateral in situ & 118 & 104 & 14 \\
\hline Ipsilateral invasive & 376 & 334 & 42 \\
\hline Contralateral invasive & 303 & 262 & 41 \\
\hline Total invasive $e^{a}$ & 768 & 677 & 91 \\
\hline Second breast event total ${ }^{a, b}$ & 886 & 781 & 105 \\
\hline \multicolumn{4}{|l|}{ Type of second events (women, $n$ ) } \\
\hline Contralateral in situ ${ }^{a}$ & 117 & 103 & 14 \\
\hline Ipsilateral invasive & 370 & 328 & 42 \\
\hline Contralateral invasive & 299 & 258 & 41 \\
\hline Total invasive ${ }^{a}$ & 725 & 637 & 88 \\
\hline Second breast event total ${ }^{a, b}$ & 825 & 728 & 97 \\
\hline
\end{tabular}

Includes the events where laterality is missing. ${ }^{2 \mathrm{~b}}$ ipsilateral in situ events were not included in the study

13.2-19.1)). Poisson regression analyses showed that women with a family history of breast cancer had almost $50 \%$ increased risk of contralateral invasive breast cancer, compared to women without a family history of breast cancer (adjusted IRR 1.5 (95 \% CI 1.0-2.0)).

Among women diagnosed with in situ breast cancer, the cumulative 10-year and 20-year risk of subsequent contralateral or ipsilateral invasive cancer was approximately $10 \%$ and $18 \%$, respectively, while the cumulative 10-year and 20-year risk of subsequent contralateral in situ breast cancer was $1 \%$ and $2 \%$, respectively (Fig. 1 ). 
Table 2 Standardized incidence ratio (SIR) of a second breast event (contralateral in situ or ipsilateral or contralateral invasive breast cancer) after diagnosis of first in situ breast cancer and its $95 \% \mathrm{Cl}$, by type of second breast event and family history

\begin{tabular}{|c|c|c|c|c|c|c|c|}
\hline & \multicolumn{2}{|l|}{ All } & \multicolumn{2}{|c|}{ No family history } & \multicolumn{2}{|c|}{ Family history } & \multirow[t]{2}{*}{ Incidence rate ratio ${ }^{d}$} \\
\hline & Number & SIR & Number & SIR & Number & SIR & \\
\hline & & $(95 \% \mathrm{Cl})$ & & $(95 \% \mathrm{Cl})$ & & $(95 \% \mathrm{Cl})$ & $(95 \%$ Cl) \\
\hline Second breast cancer ${ }^{a}$ & 886 & $5.1(4.8-5.4)$ & 781 & $5.0(4.6-5.3)$ & 105 & $6.3(5.1-7.6)$ & $1.2(1.0-1.4)$ \\
\hline Second contralateral in situ ${ }^{a}$ & 118 & $16.0(13.2-19.1)$ & 104 & $15.8(12.9-19.2)$ & 14 & $17.4(9.5-29.3)$ & $1.1(0.6-1.9)$ \\
\hline Second invasive ${ }^{b}$ & 768 & $4.6(4.2-4.9)$ & 677 & $4.4(4.1-4.7)$ & 91 & $5.6(4.5-6.9)$ & $1.2(1.0-1.5)$ \\
\hline Second ipsilateral invasive ${ }^{c}$ & 376 & $4.3(3.8-4.7)$ & 334 & $4.2(3.8-4.7)$ & 42 & $5.0(3.6-6.7)$ & $1.00(0.7-1.4)$ \\
\hline Second contralateral invasive ${ }^{c}$ & 303 & $3.4(3.1-3.8)$ & 262 & $3.3(2.9-3.7)$ & 41 & $4.8(3.5-6.5)$ & $1.5(1.0-2.0)$ \\
\hline
\end{tabular}

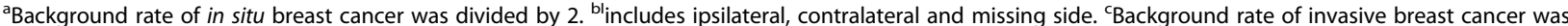
divided by $2 .{ }^{d}$ Reference group is No family history. Incidence rate ratio has been adjusted for age and year of first diagnosis of in situ cancer and time since first diagnosis

Women with in situ breast cancer and no family history had increasing risk of subsequent invasive cancer during the study period, with a SIR of 3.1 (95\% CI 2.4-3.9) in $1980-1984$, vs. 5.0 (95 \% CI 3.9-6.5) in 2000-2004 ( $P$ for trend $<0.001)$. In contrast, women with a family history did not have increased risk of subsequent invasive breast cancer over the study period (Table 3). The EAR also increased over the study period for women with no family history of breast cancer but did not increase in women with a family history (Additional file 1 : Table S1).

Overall, the relative risk of subsequent invasive breast cancer was almost twice as high for women under 40 years old at the first in situ breast cancer diagnosis compared with women over 40 years, with SIRs of 8.5 (95\% CI 6.1-11.7) and 4.4 (95 \% CI 4.1-4.8), respectively ( $P$ value $<0.001)$. Among women below 40 years, and who had a positive family history, the risk of subsequent invasive cancer was more than 14 times higher than in the general population, with a SIR of 14.3 (95\% CI 7.4-25.0).

Given that the background rates of breast cancer are highly age-dependent, we estimated the EAR in relation to age at diagnosis. While the relative risk of a subsequent invasive breast event decreased with increasing age, in both women with and without a family history of breast cancer, the overall EAR was significantly increased but was similar in women below 40 years of age at diagnosis (93.2 per 10,000 person-years; $95 \%$ CI 63.4-129.8) as compared to women over 40 (88.5 per 10,000 person-years; $95 \%$ CI 80.4-97.0) (Additional file 1: Table S1). In contrast, women with a family history of breast cancer had the highest EAR, with women under 40 years of age carrying the greatest EAR (154.1 per 10,000 person-years; $95 \%$ CI 77.1-266.3), compared to women older than 40 years at diagnosis (105.7 per 10,000 person-years; $95 \%$ CI 78.9-136.8). This suggests that both relative and absolute risks are higher with younger age of onset of in situ disease in women with a positive family history.

Finally, regardless of family history the risk of subsequent invasive cancer in the first 5 years after first in situ breast cancer was increased more than fivefold compared to the general population (SIR 5.2; $95 \%$ CI 4.7-5.7). In women with no family history there was a significant decline in both the relative and absolute risk over time, but this was not observed in women with a family history (Table 3 and Additional file 1: Table S1).

\section{Mortality}

The overall risk of death in women with in situ cancer was significantly increased by $30 \%$ compared to the general population but was highly dependent on the occurrence of a second invasive cancer event (Table 4).

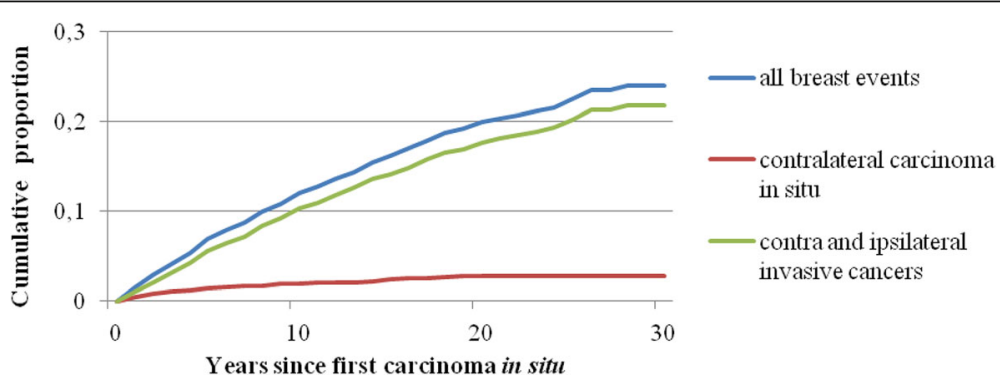

Fig. 1 Cumulative incidence of a second breast event among women diagnosed with in situ breast cancer, stratified by types of subsequent breast events 
Table 3 Standardized incidence ratio (SIR) of second invasive breast cancer (ipsilateral and contra lateral) after diagnosis of first in situ breast cancer, by year at first diagnosis, age at first diagnosis, time since first diagnosis and family history (years)

\begin{tabular}{|c|c|c|c|c|c|c|c|c|c|}
\hline & \multicolumn{3}{|l|}{ All } & \multicolumn{3}{|c|}{ No family history } & \multicolumn{3}{|c|}{ Family history } \\
\hline & Number & SIR & $95 \% \mathrm{Cl}$ & Number & SIR & $95 \% \mathrm{Cl}$ & Number & SIR & $95 \% \mathrm{Cl}$ \\
\hline \multicolumn{10}{|l|}{ Calendar year $^{a}$} \\
\hline 1980-1984 & 81 & 3.3 & $2.6-4.1$ & 72 & 3.1 & $2.4-3.9$ & 9 & 6.6 & $3.0-12.5$ \\
\hline 1985-1989 & 141 & 3.5 & $3.0-4.2$ & 123 & 3.4 & $2.8-4.0$ & 18 & 5.3 & $3.2-8.4$ \\
\hline 1990-1994 & 292 & 5.2 & $4.6-5.9$ & 259 & 5.1 & $4.5-5.8$ & 33 & 5.9 & $4.1-8.3$ \\
\hline 1995-1999 & 182 & 5.2 & $4.5-6.1$ & 160 & 5.2 & $4.4-6.0$ & 22 & 5.2 & $3.3-7.9$ \\
\hline $2000-2004$ & 72 & 5.1 & $4.0-6.4$ & 63 & 5.1 & $3.9-6.5$ & 9 & 5.5 & $2.5-10.4$ \\
\hline$P$ value & $<0.001$ & & & & $<0.001$ & & & 1 & \\
\hline \multicolumn{10}{|c|}{ Age at diagnosis (years) } \\
\hline$<40$ & 39 & 8.5 & $6.0-11.7$ & 27 & 7.2 & $4.8-10.5$ & 12 & 14.3 & $7.4-25.0$ \\
\hline $40-49$ & 173 & 4.9 & $4.2-5.7$ & 147 & 4.8 & $4.1-5.71$ & 26 & 4.7 & $3.1-6.8$ \\
\hline $50-59$ & 221 & 4.1 & $3.6-4.6$ & 189 & 3.9 & $3.4-4.5$ & 32 & 5.2 & $3.6-7.4$ \\
\hline $60-69$ & 220 & 4.6 & $4.0-5.2$ & 207 & 4.5 & $(4.0-5.2)$ & 13 & 5.2 & $2.8-8.8$ \\
\hline$\geq 70$ & 115 & 4.3 & $3.6-5.2$ & 107 & 4.2 & $(3.4-5.1)$ & 8 & 6.9 & $3.0-13.6$ \\
\hline$P$ trend & 0.008 & & & & 0.069 & & & 0.096 & \\
\hline$<40$ & 39 & 8.5 & $6.1-11.7$ & 27 & 7.2 & $4.8-10.5$ & 12 & 14.3 & 7.4-25.0 \\
\hline$>40$ & 729 & 4.4 & $4.1-4.8$ & 650 & 4.3 & $4.0-4.7$ & 79 & 5.2 & $4.1-6.4$ \\
\hline$P$ value & $<0.001$ & & & & 0.012 & & & 0.001 & \\
\hline \multicolumn{10}{|c|}{ Time since diagnosis (years) } \\
\hline $0-4$ & 401 & 5.2 & $4.7-5.7$ & 359 & 5.1 & $4.6-5.7$ & 42 & 5.5 & $3.9-7.3$ \\
\hline $5-9$ & 230 & 4.4 & $3.9-5.1$ & 197 & 4.2 & $3.6-4.8$ & 33 & 6.5 & $4.5-9.2$ \\
\hline $10-14$ & 96 & 3.4 & $2.8-4.2$ & 85 & 3.3 & $2.6-4.1$ & 11 & 4.3 & $2.1-7.7$ \\
\hline$>15$ & 41 & 3.4 & $2.4-4.6$ & 36 & 3.2 & $2.2-4.4$ & 5 & 5.9 & $1.9-13.8$ \\
\hline$P$ trend & $<0.001$ & & & & $<0.001$ & & & 0.848 & \\
\hline
\end{tabular}

${ }^{a}$ On restriction of the follow-up time to 5 years the estimates were similar but the trend tests not significant

Table 4 Standardized mortality ratio (SMR) with second breast events (contralateral in situ or ipsilateral or contralateral invasive breast cancer) after diagnosis of first in situ breast cancer and its $95 \% \mathrm{Cl}$, by type of second breast event and family history

\begin{tabular}{|c|c|c|c|c|c|c|c|c|c|c|}
\hline & \multicolumn{2}{|l|}{ All } & \multicolumn{2}{|c|}{ No family history } & \multicolumn{2}{|c|}{ Family history } & \multicolumn{2}{|l|}{$<50$} & \multicolumn{2}{|l|}{$>50$} \\
\hline & Deaths $(n)$ & SMR & Deaths $(n)$ & SMR & Deaths $(n)$ & SMR & Deaths $(n)$ & SMR & Deaths $(n)$ & SMR \\
\hline & $(95 \% \mathrm{Cl})$ & & $(95 \% \mathrm{Cl})$ & & $(95 \% \mathrm{Cl})$ & & $(95 \% \mathrm{Cl})$ & & $(95 \% \mathrm{Cl})$ & \\
\hline \multirow[t]{2}{*}{ Overall } & 1343 & 1.28 & 1258 & 1.2 & 85 & 1.44 & 122 & 2.19 & 1221 & 1.24 \\
\hline & $(1.2-1.2)$ & & $(1.2-1.4)$ & & $(1.2-1.8)$ & & $(1.8-2.6)$ & & $(1.2-1.3)$ & \\
\hline \multirow[t]{2}{*}{ No event $+2^{\text {nd }}$ contralateral in situ } & 927 & 1.01 & 875 & 1.0 & 52 & 1.02 & 58 & 1.17 & 869 & 1.00 \\
\hline & $(1.0-1.1)$ & & $(0.9-1.1)$ & & $(0.8-1.3)$ & & $(0.8-1.5)$ & & $(0.9-1.1)$ & \\
\hline \multirow[t]{2}{*}{ Second invasive ${ }^{a}$} & 132 & 2.06 & 122 & 2.03 & 10 & 2.54 & 29 & 8.03 & 103 & 1.7 \\
\hline & $(1.7-2.4)$ & & $(1.7-2.4)$ & & $(1.2-4.7)$ & & $(5.4-11.5)$ & & $(1.4-2.1)$ & \\
\hline \multirow[t]{2}{*}{ Second ipsilateral invasive } & 63 & 2.16 & 58 & 2.12 & $5^{\mathrm{b}}$ & 2.75 & 17 & 12.89 & 46 & 1.65 \\
\hline & $(1.7-2.8)$ & & $(1.6-2.7)$ & & $(0.9-6.4)$ & & $(7.5-20.6)$ & & $(1.2-2.2)$ & \\
\hline \multirow[t]{2}{*}{ Second contralateral invasive } & 55 & 1.99 & 49 & 1.92 & $6^{\mathrm{b}}$ & 2.82 & 10 & 7.85 & 45 & 1.71 \\
\hline & $(1.5-2.6)$ & & $(1.4-2.5)$ & & $(1.0-6.2)$ & & $(3.8-14.4)$ & & $(1.2-2.3)$ & \\
\hline
\end{tabular}

${ }^{a}$ Includes ipsilateral, contralateral and missing side. ${ }^{b}$ One subject had both ipsilateral and contralateral invasive breast cancer, which is why the total is $6+5=11>10$ 
Women who did not have a second invasive event following in situ breast cancer, had a similar risk of death to women in the background population (SMR 1.0 (95\% CI 1.0-1.1)). In contrast, women who were diagnosed with an invasive breast cancer event after in situ breast cancer were twice as likely to die as compared to women in the general population (SMR 2.1 (95\% CI 1.7-2.4)), with no significant differences between women with and without a family history of breast cancer.

The overall risk of death following in situ breast cancer was increased in women with a family history (SMR1.4 (95 \% CI 1.2-1.8)) and in women without family history (SMR 1.3 (95\% CI 1.2-1.4)). Given that deaths were rare at younger ages, we compared mortality among women above and below age 50 years. Women below age 50 years at the first in situ breast cancer diagnosis and who were diagnosed with a second invasive cancer, had significantly higher mortality as compared to women over 50 years at diagnosis (SMR 8.0; 95 \% CI 5.4-11.5 vs. SMR 1.7; 95 \% CI 1.4-2.0). The laterality of the second invasive event did not influence the risk of death significantly.

\section{Discussion}

In this large population-based cohort, with data from nationwide, high-quality registers, we demonstrate that women diagnosed with in situ breast cancer have a considerably increased risk of invasive breast cancer and contralateral in situ breast cancer, compared to women in the general population, with young women facing the highest risk. Having a positive family history increases the risk exclusively for a contralateral invasive breast cancer by $50 \%$ compared to not having a family history of breast cancer. The increased risk of invasive cancer persists over time, and at fifteen years after diagnosis the risk is still three times higher than in women in the general population. Meanwhile, the mortality for women with in situ breast cancer is the same as the general population, as long as invasive cancer does not occur.

In women with a positive family history, the risk of contralateral invasive breast cancer was more than four times as high as for women in the general population and almost $50 \%$ higher compared to women with no family history of breast cancer. The observed increased risk is approximately twice as high as the risk of breast cancer that is faced by women without previous breast cancer, who have a positive family history of breast cancer. There are methodological issues that may account for these differences, because our estimates assume only one breast is at risk, with a corresponding lower expected rate.

Two meta-analyses of familial risks of breast cancer report the relative risk associated with having a firstdegree relative with breast cancer as 2.1 and 1.8, respectively $[28,29]$. The observed diluted additional risk in women with a family history, i.e., only $50 \%$ increased risk of a contralateral invasive cancer, and no increased risk for ipsilateral invasive cancer or contralateral in situ cancer, as compared to women with no family history, is intriguing. We speculate that women with a positive family history were likely more prone to choose mastectomy than those without family history, which would reduce the risk of an ipsilateral cancer in these women. The reduced risk may also be a reflection of heterogeneity of the in situ breast cancer phenotype. Additional stratification into one, two or even three affected first-degree members to better quantify the hereditary component may have allowed a deeper understanding of these results.

Regardless of family history, women under 40 years of age at diagnosis had a significantly higher risk of subsequent invasive breast cancer compared to women above 40 years. These young women would experience an absolute excess risk ranging from about 8 events per 1000 person-years to as many as 15 events per 1,000 person-years depending on family history; this absolute excess risk decreases with increasing age only in women with a positive family history. Given that a younger woman with both high risk of a subsequent event and a longer life expectancy, which translates to higher cumulative risk, mastectomy may be considered to a greater extent in this patient population.

The increased relative risk of subsequent invasive breast cancer by almost $60 \%$ from the period 1980-1984 to the period 2000-2004, exclusively in women with no family history, may be related to a combination of screening and treatment patterns. A nationwide mammography screening program was introduced during the study period, which had complete national coverage by 1997 [30]. Thus, the means of detection of in situ breast cancer changed during the study period, from symptom-detected to screening-detected, with better prognosis for the latter [31]. However, in this study the risk of subsequent invasive breast cancer increased during the study period and this might reflect that with increasing mammography screening and subsequently a larger number of smaller lesions detected, the use of breast-conserving surgery became the norm from 1990 onwards [32]. In comparison to mastectomy, breast-conserving surgery poses an increased risk of both local recurrence and new ipsilateral primary cancer. In contrast, women with a positive family history had no increased risk during the study period and we speculate that these women, who had relatives with breast cancer, were more prone to choosing mastectomy.

Treatment for in situ breast cancer during the study period was performed according to regional and national guidelines [32]. Surgery involved either mastectomy or breast-conserving surgery, and since the 1990s breastconserving surgery for in situ breast cancer has been 
recommended whenever feasible. Several randomized trials, including the Swedish National DCIS study, have unanimously shown a decreased rate of ipsilateral in situ or invasive breast cancer recurrence through the addition of adjuvant radiotherapy after breast-conserving surgery $[19,33-37]$, and today, national guidelines include radiotherapy up to a total of 50 Gray after breast-conserving therapy in patients with ductal carcinoma in situ [32]. However, during most of the study period adjuvant radiotherapy was not recommended for the majority of patients who were treated with breast-conserving surgery, which might reflect the increased relative risk of a second invasive event in the latter parts of the study period when breast-conserving surgery become more frequent.

During follow up, women with no family history of breast cancer had a gradually decreasing risk of subsequent invasive breast cancer with time since diagnosis. However, 15 years after the first in situ breast cancer, the risk for an invasive breast cancer was still almost three times higher than for women in the general population. This indicates that women diagnosed with in situ breast cancer have a lifelong increased risk, which needs to be taken into account when planning their follow up.

Overall, there was no increased risk of death for women with in situ breast cancer as long as there was no second invasive event, but in women with a second invasive breast cancer the risk of death was doubled. There were no significant differences in mortality between women with and without family history of breast cancer. Young age of onset was an important predictor of death for women with in situ disease due to an increased risk for second invasive cancers and thus a substantially higher mortality, which should be taken into account when planning their treatment and follow-up.

In women with elevated risk of breast cancer, studies have shown that adjuvant endocrine therapy with a selective estrogen receptor modulator or an aromatase inhibitor reduces the risk by $40-50 \%$ [38-40], and in women with lobular and ductal cancer in situ some studies suggest that the benefits are even greater [12, 38, 41, 42]. Today, national Swedish guidelines do not support the use of adjuvant endocrine therapy after standard therapy for ductal cancer in situ, and for lobular cancer in situ surgical or adjuvant treatment is still not recommended. One must weigh the benefits of endocrine therapy in reducing second breast cancer events against an increased risk of side effects. In a systematic review and meta-analysis the number needed to treat in order for Tamoxifen to have a protective effect against all breast events was 15 and it did not reduce the risk of all-cause mortality [43].

Strengths of the current study include the populationbased design, the large sample size, complete follow up and unbiased ascertainment of family history, cancers and death. To the best of our knowledge, this is the largest study to assess the impact of a positive family history of breast cancer on risk and mortality after in situ breast cancer.

This study has a number of limitations. We have no information on the mode of detection, tumor grade or adjuvant treatment, and have not distinguished between mastectomies and breast-conserving surgery, or ductal carcinoma in situ and lobular carcinoma in situ. With this stated, a previous Swedish case-control study has shown that the risk of a subsequent invasive breast cancer was equal after lobular and ductal carcinoma in situ breast cancer [17]. One study has shown that for women with lobular carcinoma in situ, family history does not increase the risk of invasive breast cancer [12], thus among women with ductal carcinoma in situ and a positive family history, the risk estimates might be higher than shown in our study. During the study period, Sweden did not have a nationwide register on local recurrences and in the vast majority of regions, a second ipsilateral in situ breast cancer event was not reported. Therefore, new ipsilateral in situ cancer was not included in the study, as these events most probably would be underestimated.

\section{Conclusions}

Among women with in situ breast cancer, a positive family history of breast cancer increases the risk of contralateral invasive breast cancer by almost $50 \%$. The risk of subsequent invasive breast cancer and of mortality is substantially higher in younger women, which should be taken into account when planning their treatment and follow up.

\section{Additional file}

Additional file 1: Table S1. Excess additive risks (EAR) per 10,000 person-years after diagnosis of first in situ breast cancer, presented stratified by year at first diagnosis, age at first diagnosis, time since first diagnosis and family history. (DOC $45 \mathrm{~kb}$ )

\section{Abbreviations \\ Cl: confidence interval; EAR: excess additive risks; SIR: standardized incident ratio; SMR: standardized mortality ratio}

\section{Acknowledgements}

This study was financed by grants from the Swedish Research Council, the Johan and Jakob Söderbergs Foundation, Tte Swedish Breast Cancer Association, the Karolinska Institutet Doctoral foundation, the Olle Engkvist Bygg-mästare Foundation, the Swedish Cancer Foundation and the Cancer Society of Stockholm.

Funding

The study sponsors had no involvement in the study.

Availability of data and materials

All data supporting our findings can be found presented in the main paper or in supplementary files. 


\section{Authors' contributions}

$\mathrm{MH}, \mathrm{KC}, \mathrm{HS}$ and JF participated in the design of the study. $\mathrm{MH}$ and $\mathrm{KC}$ performed the data acquisition. All authors contributed to the data analysis and interpretation. MH and GE performed the statistical analysis. HS and $\mathrm{MH}$ wrote the manuscript. All authors read, reviewed and approved the manuscript.

\section{Competing interests}

The authors declare that they have no competing interests.

\section{Consent for publication}

Informed consent is not applicable as it is a register study.

\section{Ethics approval and consent to participate}

The ethical committee at Karolinska Institutet approved the study (reference number 03-071 and 2012/217-32/2).

\section{Author details}

'Department of Molecular Medicine and Surgery, Karolinska Institutet, Stockholm, Sweden. ${ }^{2}$ Saw Swee Hock School of Public Health, National University of Singapore, Singapore, Singapore. ${ }^{3}$ Department of Medical Epidemiology and Biostatistics, Karolinska Institutet, Stockholm, Sweden. ${ }^{4}$ Imaging Division, University Medical Center Utrecht, Utrecht, The Netherlands. ${ }^{5}$ Department of Surgery, National University Hospital, Singapore, Singapore. ${ }^{6}$ Department of Breast and Endocrine Surgery, Karolinska University Hospital, Stockholm, Sweden. ${ }^{7}$ Hematology Center, Karolinska University Hospital, Stockholm, Sweden.

\section{Received: 27 April 2016 Accepted: 27 September 2016}

\section{Published online: 18 October 2016}

\section{References}

1. Chuba PJ, Hamre MR, Yap J, Severson RK, Lucas D, Shamsa F, et al. Bilateral risk for subsequent breast cancer after lobular carcinoma-insitu: analysis of surveillance, epidemiology, and end results data. J Clin Oncol. 2005;23(24):5534-41.

2. Erbas B, Provenzano E, Armes J, Gertig D. The natural history of ductal carcinoma in situ of the breast: a review. Breast Cancer Res Treat 2006;97(2):135-44. Epub 2005/12/02. eng.

3. Franceschi S, Levi F, La Vecchia C, Randimbison L, Te VC. Second cancers following in situ carcinoma of the breast. Int J Cancer. 1998;77(3):392-5. Epub 1998/07/15. eng.

4. Innos K, Horn-Ross PL. Risk of second primary breast cancers among women with ductal carcinoma in situ of the breast. Breast Cancer Res Treat. 2008;111(3):531-40. Epub 2007/11/06. eng.

5. Li Cl, Malone KE, Saltzman BS, Daling JR. Risk of invasive breast carcinoma among women diagnosed with ductal carcinoma in situ and lobular carcinoma in situ, 1988-2001. Cancer. 2006;106(10):2104-12. Epub 2006/04/11. eng.

6. Robinson D, Holmberg $L$, Moller $H$. The occurrence of invasive cancers following a diagnosis of breast carcinoma in situ. Br J Cancer. 2008;99(4): 611-5. Epub 2008/07/31. eng.

7. Habel LA, Moe RE, Daling JR, Holte S, Rossing MA, Weiss NS. Risk of contralateral breast cancer among women with carcinoma in situ of the breast. Ann Surg. 1997;225(1):69-75. Pubmed Central PMCID: 1190608, Epub 1997/01/01. eng

8. Rawal R, Lorenzo Bermejo J, Hemminki K. Risk of subsequent invasive breast carcinoma after in situ breast carcinoma in a population covered by national mammographic screening. Br J Cancer. 2005;92(1):162-6. Pubmed Central PMCID: 2361754, Epub 2004/12/01. eng.

9. Levi F, Randimbison L, Te VC, La Vecchia C. Invasive breast cancer following ductal and lobular carcinoma in situ of the breast. Int J Cancer. 2005;116(5): 820-3. Epub 2005/04/20. eng

10. Warnberg F, Yuen J, Holmberg L. Risk of subsequent invasive breast cancer after breast carcinoma in situ. Lancet. 2000;355(9205):724-5. Epub 2000/03/07. eng

11. Soerjomataram I, Louwman WJ, van der Sangen MJ, Roumen RM, Coebergh JW. Increased risk of second malignancies after in situ breast carcinoma in a population-based registry. Br J Cancer. 2006;95(3):393-7. Pubmed Central PMCID: 2360642, Epub 2006/06/29. eng.
12. King TA, Pilewskie M, Muhsen S, Patil S, Mautner SK, Park A, et al. Lobular carcinoma in situ: a 29-year longitudinal experience evaluating clinicopathologic features and breast cancer risk. J Clin Oncol. 2015;33(33):3945-52.

13. Eusebi V, Feudale E, Foschini MP, Micheli A, Conti A, Riva C, et al. Long-term follow-up of in situ carcinoma of the breast. Semin Diagn Pathol. 1994;11(3): 223-35. Epub 1994/08/01. eng.

14. Warnberg F, Bergh J, Holmberg L. Prognosis in women with a carcinoma in situ of the breast: a population-based study in Sweden. Cancer Epidemiol Biomarkers Prev. 1999;8(9):769-74. Epub 1999/09/25. eng.

15. Hemminki K, Granstrom C. Familial breast carcinoma risks by morphology: a nationwide epidemiologic study from Sweden. Cancer. 2002;94(11):3063-70. Epub 2002/07/13. eng.

16. Stuart KE, Houssami N, Taylor R, Hayen A, Boyages J. Long-term outcomes of ductal carcinoma in situ of the breast: a systematic review, meta-analysis and meta-regression analysis. BMC Cancer. 2015;15:890. Pubmed Central PMCID: 4641372.

17. Warnberg F, Bergh J, Zack M, Holmberg L. Risk factors for subsequent invasive breast cancer and breast cancer death after ductal carcinoma in situ: a population-based case-control study in Sweden. Cancer Epidemiol Biomarkers Prev. 2001;10(5):495-9. Epub 2001/05/16. eng.

18. Falk RS, Hofvind S, Skaane P, Haldorsen T. Second events following ductal carcinoma in situ of the breast: a register-based cohort study. Breast Cancer Res Treat. 2011;129(3):929-38. Epub 2011/05/04. eng.

19. Emdin SO, Granstrand B, Ringberg A, Sandelin K, Arnesson LG, Nordgren $H$, et al. SweDCIS: Radiotherapy after sector resection for ductal carcinoma in situ of the breast. Results of a randomised trial in a population offered mammography screening. Acta Oncol. 2006;45(5):536-43. Epub 2006/07/26. eng.

20. Claus EB, Petruzella S, Matloff E, Carter D. Prevalence of BRCA1 and BRCA2 mutations in women diagnosed with ductal carcinoma in situ. JAMA. 2005: 293(8):964-9. Epub 2005/02/25. eng.

21. Harris EE, Schultz DJ, Peters CA, Solin LJ. Relationship of family history and outcome after breast conservation therapy in women with ducta carcinoma in situ of the breast. Int J Radiat Oncol Biol Phys. 2000;48(4): 933-41. Epub 2000/11/10. eng.

22. Ji J, Hemminki K. Risk for contralateral breast cancers in a population covered by mammography: effects of family history, age at diagnosis and histology. Breast Cancer Res Treat. 2007;105(2):229-36. Epub 2006/11/23. eng.

23. Bradley SJ, Weaver DW, Bouwman DL. Alternatives in the surgical management of in situ breast cancer. A meta-analysis of outcome. Am Surg. 1990;56(7):428-32. Epub 1990/07/01. eng.

24. Rutqvist LE, Wallgren, A. Inconsistencies in breast carcinoma registration. An investigation of 855 cases reported to the Swedish Cancer Registry. Acta Radiol Oncol. 1983:22(2):109-12.

25. Mattsson B, Wallgren A. Completeness of the Swedish Cancer Register. Nonnotified cancer cases recorded on death certificates in 1978. Acta Radiol Oncol. 1984;23(5):305-13.

26. Garne JP, Aspegren K, Moller T. Validity of breast cancer registration from one hospital into the Swedish National Cancer Registry 1971-1991. Acta Oncol. 1995:34(2):153-6.

27. Breslow NE, Day NE, editors. Statistical Methods in Cancer Research. Lyon: Volume II: The design and analysis of cohort studies; 1987.

28. Collaborative Group on Hormonal Factors in Breast cancer. Familial breast cancer: collaborative reanalysis of individual data from 52 epidemiological studies including 58,209 women with breast cancer and 101,986 women without the disease. Lancet. 2001:358(9291):1389-99. Epub 2001/11/14. eng

29. Pharoah PD, Day NE, Duffy S, Easton DF, Ponder BA. Family history and the risk of breast cancer: a systematic review and meta-analysis. Int J Cancer. 1997;71(5):800-9.

30. Olsson S, Andersson I, Karlberg I, Bjurstam N, Frodis E, Hakansson S. Implementation of service screening with mammography in Sweden: from pilot study to nationwide programme. J Med Screen. 2000;7(1):14-8.

31. Nystrom L, Andersson I, Bjurstam N, Frisell J, Nordenskjold B, Rutqvist LE. Long-term effects of mammography screening: updated overview of the Swedish randomised trials. Lancet. 2002;359(9310):909-19.

32. Breast Cancer. Report from the Regional Cancer Register Stockholm-Gotland Region 1977-2006 2011. 87]. Available from: https:/www.cancercentrum.se/ globalassets/cancerdiagnoser/brost/vardprogram/vp-brostcancer.pdf.

33. Julien JP, Bijker N, Fentiman IS, Peterse JL, Delledonne V, Rouanet P, et al. Radiotherapy in breast-conserving treatment for ductal carcinoma in situ: first results of the EORTC randomised phase III trial 10853. EORTC Breast 
Cancer Cooperative Group and EORTC Radiotherapy Group. Lancet. 2000; 355(9203):528-33. Epub 2000/02/22. eng.

34. Holmberg L, Garmo H, Granstrand B, Ringberg A, Arnesson LG, Sandelin K, et al. Absolute risk reductions for local recurrence after postoperative radiotherapy after sector resection for ductal carcinoma in situ of the breast. J Clin Oncol. 2008;26(8):1247-52. Epub 2008/02/06. eng.

35. Fisher B, Costantino J, Redmond C, Fisher E, Margolese R, Dimitrov N, et al. Lumpectomy compared with lumpectomy and radiation therapy for the treatment of intraductal breast cancer. N Engl J Med. 1993;328(22):1581-6. Epub 1993/06/03. eng.

36. Fisher B, Dignam J, Wolmark N, Mamounas E, Costantino J, Poller W, et al. Lumpectomy and radiation therapy for the treatment of intraductal breast cancer: findings from National Surgical Adjuvant Breast and Bowel Project B-17. J Clin Oncol. 1998;16(2):441-52. Epub 1998/02/20. eng.

37. Houghton J, George WD, Cuzick J, Duggan C, Fentiman IS, Spittle M. Radiotherapy and tamoxifen in women with completely excised ductal carcinoma in situ of the breast in the UK, Australia, and New Zealand: randomised controlled trial. Lancet. 2003;362(9378):95-102. Epub 2003/07/18. eng.

38. Cuzick J, Sestak I, Forbes JF, Dowsett M, Knox J, Cawthorn S, et al. Anastrozole for prevention of breast cancer in high-risk postmenopausal women (IBIS-II): an international, double-blind, randomised placebocontrolled trial. Lancet. 2014;383(9922):1041-8.

39. Goss PE, Ingle JN, Ales-Martinez JE, Cheung AM, Chlebowski RT, WactawskiWende J, et al. Exemestane for breast-cancer prevention in postmenopausal women. N Engl J Med. 2011;364(25):2381-91.

40. Vogel VG, Costantino JP, Wickerham DL, Cronin WM, Cecchini RS, Atkins $\mathrm{JN}$, et al. Update of the National Surgical Adjuvant Breast and Bowel Project Study of Tamoxifen and Raloxifene (STAR) P-2 Trial: Preventing breast cancer. Cancer Prev Res. 2010;3(6):696-706. Pubmed Central PMCID: 2935331.

41. Fisher B, Costantino JP, Wickerham DL, Redmond CK, Kavanah M, Cronin WM, et al. Tamoxifen for prevention of breast cancer: report of the National Surgical Adjuvant Breast and Bowel Project P-1 Study. J Natl Cancer Inst. 1998;90(18):1371-88.

42. Allred DC, Anderson SJ, Paik S, Wickerham DL, Nagtegaal ID, Swain SM, et al. Adjuvant tamoxifen reduces subsequent breast cancer in women with estrogen receptor-positive ductal carcinoma in situ: a study based on NSABP protocol B-24. J Clin Oncol. 2012;30(12):1268-73. Pubmed Central PMCID: 3341142

43. Staley H, McCallum I, Bruce J. Postoperative Tamoxifen for ductal carcinoma in situ: Cochrane systematic review and meta-analysis. Breast. 2014;23(5):546-51.

\section{Submit your next manuscript to BioMed Central and we will help you at every step:}

- We accept pre-submission inquiries

- Our selector tool helps you to find the most relevant journal

- We provide round the clock customer support

- Convenient online submission

- Thorough peer review

- Inclusion in PubMed and all major indexing services

- Maximum visibility for your research

Submit your manuscript at www.biomedcentral.com/submit

) Biomed Central 